\section{Effect of room temperature and cooled intraocular irrigating solution on the cornea and anterior segment inflammation after phacoemulsification: a randomized clinical trial}

\begin{abstract}
Purpose To compare the effects of cooled and room temperature BSS Plus solution on the central corneal thickness (CCT), anterior segment inflammation, and corneal endothelium in patients undergoing phacoemulsification.

Methods In this prospective, randomized study, 70 consecutive patients undergoing phacoemulsification were assigned to one of two groups: Group 1 (controls) $(n=35)$ received BSS Plus at a room temperature of

$23^{\circ} \mathrm{C}$ and Group 2 (cases; $n=35$ ) received BSS

Plus cooled at $10^{\circ} \mathrm{C}$. In both the groups, the percentage of difference for CCT, absolute change in endothelial cell density, and coefficient of variation (CV) from preoperative to postoperative periods was analysed. The presence of anterior chamber flare and cells were compared postoperatively between the two groups.
\end{abstract}

Iladevi Cataract and IOL Research Center, Raghudeep Eye Clinic, Memnagar, Ahmedabad, Gujarat, India

Correspondence: AR Vasavada, lladevi Cataract \& IOL Research Center, Raghudeep Eye Clinic, Gurukul Road, Memnagar, Ahmedabad 380052, India

Tel: + 91792749 2303, 2749 0909;

Fax: +9179 27411200 .

E-mail: icirc@

abhayvasavada.com

Received: 14 February 2008 Accepted in revised form: 24 May 2008

Published online: 27 June 2008
Results There was no significant difference in percentage change for CCT from preoperative to postoperative days 1,7 , and 30 between the two groups $(P=0.30, P=0.56$, and $P=0.52)$. There was no statistically significant difference in the ECD loss $(P=0.19)$ and $C V$ $(P=0.88)$ at 1 month between the two groups. The influence of the solutions on anterior chamber flare and cells was not statistically significant between the two groups on the first postoperative day $(P=0.17, P=0.11)$. Conclusions The temperature of the BSS Plus solution did not affect any parameter of the
MR Praveen, AR Vasavada, R Shah and

VA Vasavada study. The use of moderately cooled BSS had no detectable effect and benefit on the outcome of the surgery.

Eye (2009) 23, 1158-1163; doi:10.1038/eye.2008.187; published online 27 June 2008

Keywords: cooled BSS plus; room temperature BSS plus; phacoemulsification

\section{Introduction}

The development of new intraocular surgical techniques has created an increasing demand for an intraocular irrigating solution that will maintain the integrity and function of intraocular structures. The clinical manifestations of corneal oedema and visual loss constitute a serious problem after routine cataract extraction, especially in patients with preexisting endothelial disease or endothelial damage resulting from previous intraocular surgery, inflammation, or trauma. ${ }^{1}$ Moreover, when the surgical procedure involves the prolonged use of large volumes of intraocular irrigating solutions, corneal oedema is a frequent complication. ${ }^{2,3}$ Hypothermia has been used to protect against ischaemia in cardiac surgery, urological surgery, and neurosurgery and also for the preservation of the ischaemic bowel. ${ }^{4-8}$ Hypothermic conditions lower metabolic rates, thereby decreasing the demand for oxygen. ${ }^{9}$ Recent work has extended this interest to the effects of intraoperative 
hypothermic perfusion on the retinovascular tissue. ${ }^{10}$ The functional and ultrastructural changes that occur in the cornea due to controlled freezing have been studied extensively. ${ }^{11-13}$ In addition to the chemical composition of the irrigating solution and the intraoperative effect of dissipating heat from the vibrating phaco needle, the temperature of the irrigating solution has also been implicated as a significant factor in determining the postoperative outcome of the surgery. ${ }^{14} \mathrm{~A}$ few surgeons have suggested that cooling the irrigating solution may not only help maintain the intraoperative mydriasis, but it may also prevent postoperative corneal swelling. ${ }^{15}$ Thus, some surgeons use irrigating solutions that have been refrigerated, whereas others prefer solutions maintained at room temperature. ${ }^{14}$ This study evaluated whether cooled BSS Plus as an irrigating solution has any impact on the central corneal thickness (CCT), anterior segment inflammation, and corneal endothelium as compared to the room temperature solution in patients undergoing phacoemulsification.

\section{Materials and methods}

This prospective randomized surgeon, examiner, and patient-masked study comprised 70 consecutive agematched and sex-matched patients with age-related cataract who underwent phacoemulsification at Iladevi Cataract and IOL Research Centre from March to July 2005. Informed consent was obtained from all the patients before enrolling them in the study. A single eye of each patient was recruited for the study. The following inclusion criteria were exercised: patients older than 45 years with age-related cataract, those with pupils dilating more than $7 \mathrm{~mm}$ with otherwise normal eyes, and the presence of any type of cataract from grades 1-3 based on Emery's classification. Exclusion criteria were the presence of glaucoma, shallow anterior chamber, high myopia (axial length $>27.0 \mathrm{~mm}$ ), pseudoexfoliation, coexisting corneal endothelial disease, anterior and posterior synechiae, uveitis, previous ocular surgeries, traumatic cataract, subluxated cataracts, and patients allergic to dilating drops. All patients underwent preoperative examinations including slit-lamp evaluations.

The sample size was computed using observations from the pilot study. Instead of calculating an absolute difference in CCT between the groups, we calculated the percentage of increase in postoperative values at day 1 as compared to the preoperative measurements. We assumed a $2 \%$ difference between the two groups to be biequivalent. On the basis of this assumption, we estimated that a sample size of 35 patients will have $90 \%$ power to prove equivalence taking an SD of $1 \%$ for percentage change obtained from our pilot study.
An ultrasound pachymetry using OcuScan (Alcon) was performed to measure the corneal thickness; noncontact specular microscopy helped to gauge the corneal endothelial cell density (ECD). After generating three acceptable values for each eye, an average value was obtained. A non-contact specular examination was carried out using the Konan non-contact Roboc-X Sp 8000 machine to evaluate the corneal endothelium. The patients were instructed to look straight ahead into the built-in fixation targets. The endothelium was visualized on an incorporated screen. The endothelial cell count was obtained using a built-in image analysis software. On each image, 100 cells were manually counted.

Subsequently, images were printed out with the analysed data. The cells were analysed with the Konan computerassisted analysis programme using the dot method. This method is semiautomatic and the operator has to hand digitize the centre of each cell in a contiguous group of 100 cells. The computer algorithm calculates the ECD, mean cell area, and coefficient of variation of the cell area.

All the enrolled patients were randomly assigned to one of the two treatment groups. We used an envelope system to facilitate randomization. In this system, sequenced and sealed envelopes containing one of the two options were prepared before the commencement of this study. Allocation concealment was followed. An unscrubbed nurse in the operation theatre opened the envelope and assigned the prescribed option (Group 1 or Group 2) to the patient. Group 1 comprised eyes in which the BSS Plus solution was kept at a room temperature of $23^{\circ} \mathrm{C}$. Group 2 comprised eyes in which the BSS Plus solution was cooled to approximately $10^{\circ} \mathrm{C}$. A constant temperature of around $23^{\circ} \mathrm{C}$ was maintained in the operation theatre. In Group 2, BSS Plus solution was placed in a refrigerator at $4^{\circ} \mathrm{C}$ for $12 \mathrm{~h}$ overnight. The beaker containing the cooled BSS was also refrigerated overnight. Before starting the surgeries for both the groups, BSS Plus was collected in a beaker using thorough aseptic precautions and the temperature was recorded using Fischer's scientific digital thermometer. When the surgery was being performed, the temperatures of the solutions were recorded at 23 and $10^{\circ} \mathrm{C}$ in groups 1 and 2, respectively. An experienced surgeon (ARV) performed all the surgeries using topical anaesthesia and a standardized surgical technique. Two paracentesis incisions of $1 \mathrm{~mm}$ were made in the clear cornea. Thereafter, the soft shell technique was used. A small amount of Viscoat ${ }^{\mathbb{R}}$ (Chondroitin sulphate, Alcon Laboratories, Forth Worth, TX, USA) was injected after which the anterior chamber was filled with highmolecular weight Provisc ${ }^{\circledR}$ (sodium hyaluronate 1.0\%, Alcon Laboratories), which pushed the Viscoat ${ }^{\circledR}$ towards the cornea and coated the endothelium. ${ }^{16}$ A $2.2 \mathrm{~mm}$ 
temporal clear corneal tunnel was fashioned. A cystome was used to make a small nick in the anterior capsule, and subsequently the flap was elevated. Using Utrata's capsulorhexis forceps, approximately $5 \mathrm{~mm}$ capsulorhexis was performed. A thorough, copious, gentle hydrodissection preceded rotation of the nucleus. Emulsification was performed with the Legacy (Alcon Laboratories) phacoemulsifier using standardized surgical techniques described elsewhere. ${ }^{17,18}$ This was followed by bimanual irrigation and aspiration to ensure thorough and complete cortex removal. An AcrySof (model: SN60AT, Alcon Laboratories) IOL was implanted in the capsular bag. Bimanual irrigation and aspiration were used to remove the residual viscoelastic substance trapped beneath the IOL. The intraoperative surgical time, fluid usage, and effective phaco time (EPT) were also measured. To obtain the primary outcome measures, CCT was recorded and compared in both the groups on the day before the surgery and on postoperative days 1, 7 and at 1 month. Similarly, the ECD and coefficient of variation $(\mathrm{CV})$ were also measured and compared between the two groups on the day before the surgery and at 1 month postoperatively. On the first postoperative day, the presence of anterior chamber flare and cells was also recorded and compared between the two groups. Anterior chamber cells and flare were measured using Hogan's criteria on the slit lamp. After adjusting for intraoperative parameters such as EPT, amount of fluid used, and surgical time, the MannWhitney $U$-test was utilized to compare CCT, ECD, CV, and anterior chamber flare and cells in both the groups at each point in time. Further, the values of CCT, EPT, and surgical time were clubbed so as to form two equal groups using the median. The first group consisted of values from the lowest observation till the middle value of the median, and the other group consisted of values greater than the median. The secondary observation was the anterior segment inflammation on the first postoperative day. A single observer who was masked to the temperature of the solutions used recorded all the postoperative observations. This ensured a total lack of any kind of bias while evaluating the outcome measures.

\section{Results}

Preoperatively, the mean CCT in Group $1(n=35)$ was $520 \pm 34$, whereas in Group $2(n=35)$, it was $527 \pm 36$. There was no significant difference in mean CCT between the two groups $(P=0.12)$. Postoperatively, the mean CCT at day 1 was $557 \pm 38$ in Group 1 vs $573 \pm 38$ in Group 2; at day 7, it was $533 \pm 51$ in Group 1 vs $543 \pm 51$ in Group 2; at 1 month, it was $520 \pm 42$ in Group 1 vs $535 \pm 42$ in Group 2. No significant difference in percentage change for CCT was documented between the two groups during the following specified points of time: postoperative days 1,7 , and at 1 month $(P=0.30$, $P=0.56$, and $P=0.52$ ), respectively (Table 1 ).

Preoperatively, the mean ECD in Group 1 was $2573 \pm 198$, whereas in Group 2, it was $2540 \pm 179$. The preoperative $\mathrm{CV}$ was $41 \pm 12$ in Group 1 and $40 \pm 6$ in Group 2. One month postoperatively, the mean ECD was $2648 \pm 165$ in Group 1 and $2556 \pm 208$ in Group 2. There was no statistically significant difference in ECD loss values between the two groups $(P=0.19)$. Similarly, the mean CV postoperatively at 1 month was $44 \pm 15$ in Group 1 and $42 \pm 8$ in Group 2. No significant difference in percentage change of $\mathrm{CV}$ values from preoperative to 1 month postoperative was noted between the two groups $(P=0.88$; Table 1$)$. The influence on anterior chamber flare and cells was not statistically significant between the two groups when evaluated on the first postoperative day ( $P=0.17$ and $P=0.11$; Table 2$)$. When the eyes in both the groups were subjected to slit-lamp examinations, no statistically significant difference in the corneal status was noted in terms of corneal oedema (localized or diffuse), descements folds, and corneal clarity $(P=1.00$; Table 2$)$.

Further, after adjusting for intraoperative parameters such as EPT, amount of fluid used, and surgical time, there was no statistically significant difference in preoperative and postoperative values of corneal thickness between the two groups. Similarly, there were no differences in ECD and CV values between the two groups at 1 month postoperatively (Table 3 ). Finally, on slit-lamp examination, no significant difference was

Table 1 A comparison of the difference of preoperative and postoperative central corneal thickness, endothelial cell density and coefficient of variation between the two groups

\begin{tabular}{|c|c|c|c|c|c|c|c|}
\hline & \multicolumn{3}{|c|}{ Room temperature BSS plus } & \multicolumn{3}{|c|}{ Cooled BSS plus } & \multirow[t]{2}{*}{ P-value } \\
\hline & Preoperative & Postoperative & $\%$ difference & Preoperative & Postoperative & $\%$ difference & \\
\hline Day -1 CCT & $520 \pm 34$ & $557 \pm 38$ & $7.2 \pm 5.8$ & $527 \pm 36$ & $573 \pm 38$ & $8.7 \pm 9.03$ & 0.30 \\
\hline Day -7 CCT & $520 \pm 34$ & $533 \pm 51$ & $2.68 \pm 9.6$ & $527 \pm 36$ & $543 \pm 51$ & $3.09 \pm 5.06$ & 0.56 \\
\hline Day -30 CCT & $520 \pm 34$ & $520 \pm 42$ & $0.15 \pm 8.8$ & $527 \pm 36$ & $535 \pm 42$ & $1.51 \pm 4.9$ & 0.52 \\
\hline $\mathrm{CD}$ & $2573 \pm 198$ & $2648 \pm 165$ & $3.5 \pm 10.18$ & $2540 \pm 179$ & $2556 \pm 208$ & $0.87 \pm 8.3$ & 0.19 \\
\hline $\mathrm{CV}$ & $41 \pm 12$ & $44 \pm 15$ & $17.9 \pm 54.0$ & $40 \pm 6$ & $42 \pm 8$ & $8.0 \pm 27.5$ & 0.88 \\
\hline
\end{tabular}

$\mathrm{CCT}=$ central corneal thickness; $\mathrm{CD}=$ cell density; $\mathrm{CV}=$ coefficient of variation. 
Table 2 A comparison of postoperative anterior segment inflammation and corneal status between the two groups

\begin{tabular}{|c|c|c|c|c|c|c|}
\hline & \multicolumn{2}{|c|}{ Cells } & \multicolumn{2}{|c|}{ Flare } & \multicolumn{2}{|c|}{ Cornea } \\
\hline & $1+2$ & $3+4$ & $1+2$ & $3+4$ & Clear & Abnormal \\
\hline Room temperature BSS Plus & $29(83 \%)$ & $6(17 \%)$ & $32(91 \%)$ & $3(9 \%)$ & $27(77 \%)$ & $8(3 \%)$ \\
\hline Cooled BSS Plus & $23(66 \%)$ & $12(34 \%)$ & $26(74 \%)$ & $9(26 \%)$ & $27(77 \%)$ & $8(23 \%)$ \\
\hline P-value & $P=0.171$ & & $P=0.11$ & & $P=1.00$ & \\
\hline
\end{tabular}

Fisher's exact two-sided test.

Table 3 A comparison of influence of volume used, EPT, and surgical time on central corneal thickness, ECD, and CV between the two groups

\begin{tabular}{|c|c|c|c|c|c|c|c|c|c|c|c|c|}
\hline \multirow[b]{2}{*}{ Surgical time } & & \multicolumn{2}{|r|}{$R T$} & \multicolumn{2}{|c|}{ Cooled } & \multirow[b]{2}{*}{ P-value } & & \multicolumn{2}{|c|}{$R T$} & \multicolumn{2}{|c|}{ Cooled } & \multirow[b]{2}{*}{ P-value } \\
\hline & & $\mathrm{N}$ & $M R$ & $\mathrm{~N}$ & $M R$ & & & $\mathrm{~N}$ & $M R$ & $\mathrm{~N}$ & $M R$ & \\
\hline \multirow[t]{3}{*}{ Up to median } & Percentage of difference (preoperative day 1) & 21 & 19.9 & 18 & 20.94 & 0.23 & \multirow[t]{3}{*}{$\begin{array}{l}\text { Above } \\
\text { median }\end{array}$} & 5 & 13 & 21 & 13.62 & 0.87 \\
\hline & Percentage of difference (preoperative day 7) & 30 & 22.67 & 14 & 22.14 & 0.90 & & 5 & 18.60 & 21 & 12.29 & 0.09 \\
\hline & Percentage of difference (preoperative day 30 ) & 30 & 21.43 & 14 & 24.79 & 0.42 & & 5 & 15.40 & 21 & 13.05 & 0.53 \\
\hline \multicolumn{13}{|l|}{ EPT } \\
\hline \multirow[t]{3}{*}{ Up to median } & Percentage of difference (preoperative day 1) & 29 & 18.4 & 6 & 17.33 & 0.86 & \multirow[t]{3}{*}{$\begin{array}{l}\text { Above } \\
\text { median }\end{array}$} & 6 & 14.33 & 29 & 18.76 & 0.33 \\
\hline & Percentage of difference (Preoperative day 7) & 29 & 18.28 & 6 & 16.67 & 0.72 & & 6 & 17.17 & 29 & 18.17 & 0.82 \\
\hline & Percentage of difference (preoperative day 30) & 29 & 17.72 & 6 & 19.33 & 0.72 & & 6 & 15.17 & 29 & 18.59 & 0.45 \\
\hline \multicolumn{13}{|l|}{ Volume } \\
\hline \multirow[t]{3}{*}{ Up to median } & Percentage of difference (preoperative day 1) & 21 & 19.19 & 18 & 20.94 & 0.63 & \multirow[t]{3}{*}{$\begin{array}{l}\text { Above } \\
\text { median }\end{array}$} & 14 & 14 & 17 & 17.65 & 0.26 \\
\hline & Percentage of difference (preoperative day 7) & 21 & 20.43 & 18 & 19.50 & 0.8 & & 14 & 16.64 & 17 & 15.47 & 0.72 \\
\hline & Percentage of difference (preoperative day 30) & 21 & 18.05 & 18 & 22.28 & 0.25 & & 14 & 16.79 & 17 & 15.35 & 0.66 \\
\hline
\end{tabular}

$\mathrm{CV}=$ coefficient of variation; $\mathrm{ECD}=$ endothelial cell density; $\mathrm{EPT}=$ effective phaco time; $\mathrm{MR}=$ mean rank; $\mathrm{N}=$ number of eyes; $\mathrm{RT}=$ room temperature; Mann-Whitney $U$-test performed for the analysis.

recorded in anterior segment inflammation and the corneal status in terms of corneal oedema (localized or diffuse), descemet's folds, and corneal clarity between the two groups (Table 4).

\section{Discussion}

There is a direct correlation between the extent of surgical trauma and endothelial cell damage. Thus, the surgeon's skill and the accuracy of the surgical technique are essential in reducing endothelial damage. The corneal endothelium regulates stromal hydration and corneal transparency by the endothelial mechanical barrier and active pump function. As far as the temperatures of the irrigating solutions are concerned, a solution at $5^{\circ} \mathrm{C}$ is considered to be hypothermic, whereas one at $23^{\circ} \mathrm{C}$ is normothermic. ${ }^{19} \mathrm{~A} 10^{\circ} \mathrm{C}$ decrease in the temperature of the ocular tissue can reduce the metabolic activity of the cornea by as much as $50 \% .^{20} \mathrm{~A}$ few authors ${ }^{21}$ have proposed that ocular hypothermia achieved with the use of a refrigerated infusion fluid might reduce ocular tissue damage during intraocular surgical procedures. In a study carried out on rabbit eyes, a few authors evaluated the effect on the corneal endothelium when it was refrigerated and room temperature irrigating solutions were used. They observed that when refrigerated solutions were used, the corneal thickness in the eyes was not fully reversed by the end of the assessment period, although it had progressively reduced. In contrast, corneas exposed to room temperature solutions returned to their normal thickness in the course of the experiment. This indicates that if irrigating solutions are stored in refrigerators, they should be brought to room temperature before they are used. ${ }^{19}$

In another study, ${ }^{2}$ while evaluating the effect of cooled irrigating solutions during phacoemulsification on postoperative blood aqueous barrier, the temperatures of the cooled and room temperature irrigating solutions were 9.6 and $22^{\circ} \mathrm{C}$, respectively, when measured at the phaco tip. In our study, the temperature of cooled BSS 
Table 4 A comparison of influence of volume used, EPT, and surgical time on corneal status and anterior chamber cells and flare between the two groups

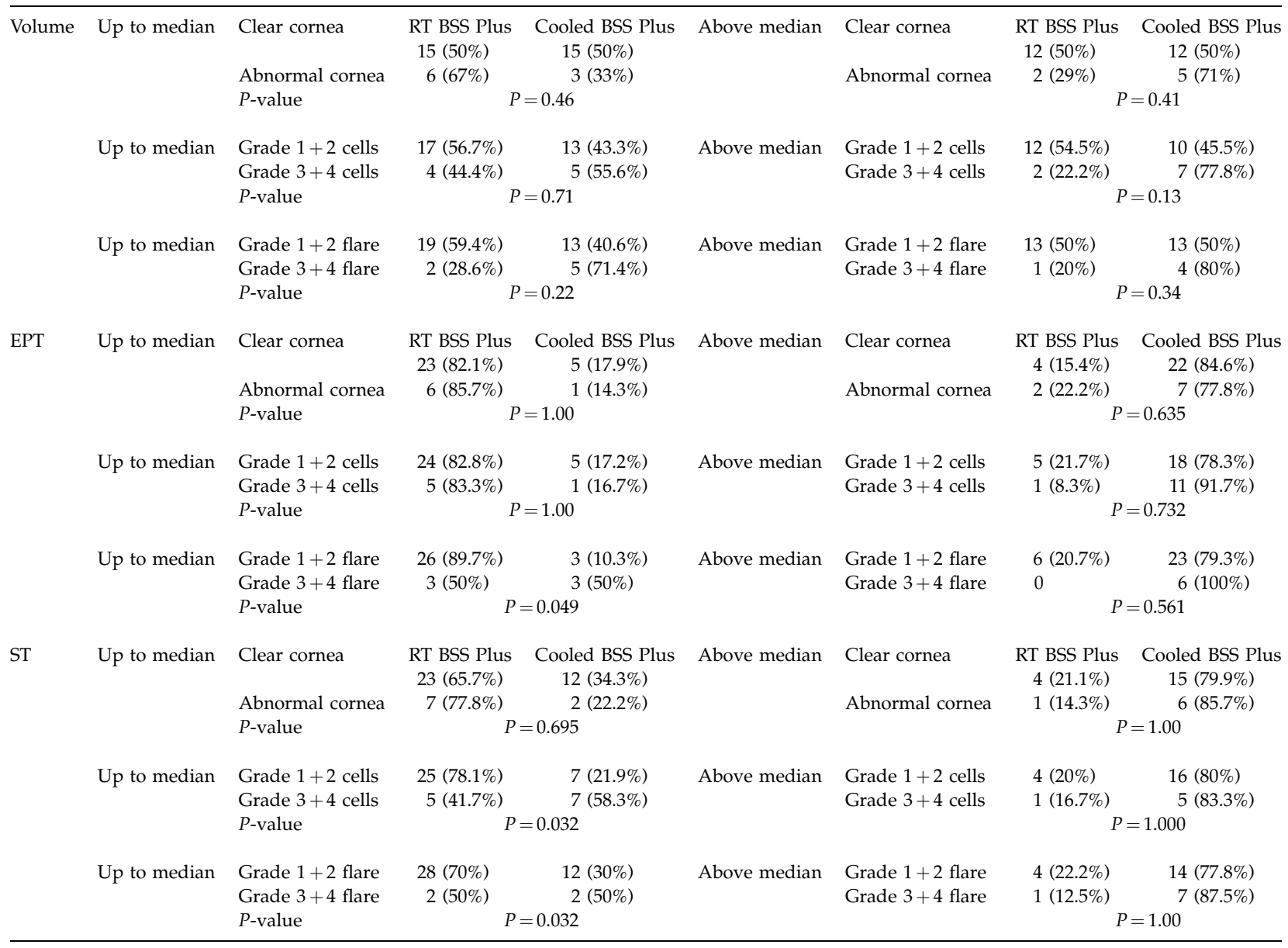

$\mathrm{EPT}=$ effective phaco time; $\mathrm{RT}=$ room temperature; $\mathrm{ST}=$ surgical time.

Plus was recorded consistently at about $10^{\circ} \mathrm{C}$ when measured in the cooled beaker. However, we did not measure the temperature of the BSS Plus at the phaco tip.

The results of this study suggest that after adjusting the volume of fluid used, surgical time, and EPT, no significant differences were documented in anterior segment inflammation (cells and flare), CCT, ECD, CV, and corneal status (in terms of clear cornea, stromal oedema, and descemet's folds) while using either cooled BSS Plus or room temperature BSS Plus solutions at postoperative days 1,7 , and at 1 month. In this study, we used non-contact specular microscopy to evaluate ECD and CV. There are few studies ${ }^{22}$ that have compared the accuracy of measuring the mean cell size in the corneal endothelium with the contact wide field Keeler Konan Sp 3300 specular microscope and the Konan Noncan Robo Co. SP 8000, and they have concluded that the accuracy of measurement with the two instruments was similar, but the reproducibility was higher with the latter. In our study, CCT was measured using ultrasound pachymetry by a single observer. Previous reports ${ }^{23,24}$ have demonstrated a high intraobserver reproducibility using ultrasound pachymetry measurements.

In another clinical study, it was documented that the influence of the temperature of the irrigating solution on the postoperative corneal thickness was not statistically significant. It was further observed that a decrease in endothelial cell count was independent of the temperature of the solution used. ${ }^{14}$ In another in vivo experiment on rabbit eyes, it was observed that when the anterior chamber was perfused with cold irrigating solution, the swelling was more persistent than that observed in eyes exposed to irrigating solutions at room temperature. This indicates that refrigerated irrigation solutions should be warmed before use. ${ }^{19}$ In another clinical report, ${ }^{20}$ it was documented that cooled intraocular irrigating solutions significantly reduced inflammation on the first postoperative day. However, it was further observed that inflammation persisted for a week and the eyes returned to normal two weeks after surgery. On the basis of these observations, it was suggested that cooled irrigating solutions appear to 
inhibit acute blood aqueous barrier disturbance but delay and possibly prolong the inflammation when compared with irrigating solutions at room temperature. In a study conducted on rabbit eyes, it was observed that cooled irrigating solutions lowered fibrin production and postoperative inflammation as compared with solutions at room temperature. ${ }^{21}$ It has been hypothesized by others ${ }^{9}$ that the hypothermic effect may be due to a generalized slowing down in the tissue metabolism and enzymatic reactions as well as decreased uveal blood flow. Our observations contradict these findings. In this study, when the eyes in both the groups were subjected to slit-lamp examination, we did not find any significant difference in anterior segment inflammation on the first postoperative day.

To our knowledge, there are very few published reports on the effects of irrigating solutions maintained at different temperatures during phacoemulsification in human subjects. Our results agree with published data that a temperature lower than the room temperature does not affect postoperative corneal parameters and inflammation. We conclude that the use of moderately cooled BSS Plus had no detectable effect and benefit on the outcome of phacoemulsification.

\section{References}

1 Dohlman $\mathrm{CH}$, Hyndiuk RA. Subclinical and manifest corneal edema after cataract extraction. Symposium on the Cornea. Transactions of the New Orleans Academy of Ophthalmology. CV Mosby Co.: St Louis, 1972, pp 224-235.

2 Straatsma BR. Summary, symposium: surgery of the vitreous body. Trans Am Acad Ophthalmol Otolaryngol 1978; 77: 216-220.

3 Emery JM, Paton D. Phacoemulsification: a survey of 2875 cases. Trans Am Acad Ophthalmol Otolaryngol 1974; 78: OP31-OP34

4 McDowall DG. The current usage of hypothermia in British neurosurgery. Br J Anaesth 1971; 43: 1084-1087.

5 Swan H. Clinical hypothermia: a lady with a past and some promise for the future. Surgery 1973; 73: 736-758.

6 Mcgill C, Taylor B, Acland R, Flint L. Effects of cooling and intraluminal antiseptics on ischemia in small bowel and colon. Surg Forum 1977; 28: 424-425.

7 Musacchia XJ. Helium cold hypothermia, an approach to depressed metabolism and thermoregulation. In: Jansky L,
Musacchia XJ (eds). Regulation of Depressed Metabolism and Thermogenesis. Thomas: Springfield IL, 1976, pp 137-157.

8 Van Horn DL, Hanna C, Schultz RO. Corneal cryopreservation. II. Ultrastructural and viability changes. Arch Ophthalmol 1970; 84: 655-667.

9 Van Horn DL. Functional and ultrastructural changes in cryopreserved corneas. Arch Ophthalmol 1973; 90: 312-318.

10 Edelhauser HF. Functional survival of cryopreserved corneal tissue. In: Capella JA, Edelhauser HF, Van Horn DL (eds). Corneal Preservation. Springfield: Thomas, 1973, pp 280-286.

11 Joussen AM, Barth U, Cubuk H, Koch HR. Effect of irrigation solution and irrigation temperature on the cornea and pupil during phacoemulsification. J Cataract Refract Surg 2000; 26: 392-397.

12 Ernest PH. Corneal lip tunnel incision. J Cataract Refract Surg 1994; 20: 154-157.

13 Arshinoff SA. Dispersive-cohesive viscoelastic soft shell technique. J Cataract Refract Surg 1999; 25: 167-173.

14 Vasavada AR, Singh R. Step-by-step, chop in situ and separation of very dense cataracts. J Cataract Refract Surg 1998; 24: 156-159.

15 Vasavada AR, Raj S. Step-down technique. J Cataract Refract Surg 2003; 29: 1077-1079.

16 May DR, Freedland RJ, Charles S, Wang C, Bakos J. Ocular hypothermia: anterior chamber perfusion. Br J Ophthalmol 1983; 67: 808-813.

17 Freeman RD, Fatt T. Environmental influences on ocular temperature. Invest Ophthalmol Visual Sci 1973; 12: 596-602.

18 Mannis MJ, Miller RB, Carlson EC. Effect of hypothermic perfusion on corneal endothelial morphology. $\mathrm{Br} J$ Ophthalmol 1983; 67: 804-807.

19 Yagoubi MI, Armitage WJ, Diamond J, Easty DL. Effects of irrigation solutions on corneal endothelial function. $\mathrm{Br} J$ Ophthalmol 1994; 78: 302-306.

20 Findl O, Amon M, Kruger A, Petternel V, Schauerberger J. Effect of cooled intraocular irrigating solution on the bloodaqueous barrier after cataract surgery. J Cataract Refract Surg 1999; 25: 566-568.

21 Jabbour NM, Schepens CL, Buzney SM. Local ocular hypothermia in experimental intraocular surgery. Ophthalomolgy 1988; 95: 1687-1690.

22 Landesz M, Siersema JV, Van Rij G. Comparative study of three semi automated specular microscopes. J Cataract Refract Surg 1995; 21: 409-416.

23 Wheeler NC, Morantes CM, Kristensen RM. Reliability coefficients of three corneal pachymeters. Am J Ophthalmol 1992; 113: 645-651.

24 Tam ES, Rootman DS. Comparison of central corneal thickness measurements by specular microscopy, ultrasound pachymetry, and ultrasound biomicroscopy. J Cataract Refract Surg 2003; 29: 1179-1184. 